\title{
The great breathlessness of cardiopulmonary diseases
}

\author{
Robert Naeije ${ }^{1,2}$ and Vitalie Faoro ${ }^{2}$ \\ Affiliations: ${ }^{1}$ Dept of Cardiology, Erasme University Hospital, Brussels, Belgium. ${ }^{2}$ Dept of Cardiorespiratory \\ Exercise Physiology, Faculty of Motor Sciences, Université Libre de Bruxelles, Brussels, Belgium.
}

Correspondence: Robert Naeije, Dept of Pathophysiology, Erasme Campus of the Université Libre de Bruxelles, 808 Lennik Road, B-1070 Brussels, Belgium. E-mail: rnaeijedulb.ac.be

@ERSpublications

Wasted ventilation is a major cause of dyspnoea, and is evaluated by cardiopulmonary exercise testing with blood gases http://ow.ly/OIQa30hK8nU

Cite this article as: Naeije R, Faoro V. The great breathlessness of cardiopulmonary diseases. Eur Respir J 2018; 51: 1702517 [https://doi.org/10.1183/13993003.02517-2017].

Shortness of breath is related to a loss of ventilatory efficiency $[1,2]$. Wasted ventilation is proportional to the ratio of ventilation $\left(V^{\prime} \mathrm{E}\right)$ to carbon dioxide output $\left(V^{\prime} \mathrm{CO}_{2}\right)$ taken as a measure of metabolic rate. Excessive $V^{\prime} \mathrm{E} / V^{\prime} \mathrm{CO}_{2}$ measured during an exercise stress test is uniformly associated with a decreased life expectancy in cardiorespiratory diseases. Therefore, as argued by WEATHERALD et al. [3] in a scholarly fashion in the present issue of the European Respiratory Journal, cardiopulmonary exercise testing with measurements of ventilation and gas exchange have to be part of the initial evaluation and follow-up of any patient with a cardiac or a respiratory condition.

The limits of normal of $V^{\prime} \mathrm{E} / V^{\prime} \mathrm{CO}_{2}$ relationships vary from 21 to 31, with an average at 26 [4]. The relationship of $V^{\prime} \mathrm{E}$ to $V^{\prime} \mathrm{CO}_{2}$ is usually defined by the slope of a linear regression on multipoint coordinates from resting to maximum exercise. Considering $V^{\prime} \mathrm{E} / V^{\prime} \mathrm{CO}_{2}$ at the anaerobic threshold only (or at its lowest value, which is close) during an exercise test decreases variability because at that point dead space is the lowest and ventilation not yet stimulated by metabolic acidosis [4]. But even so, individual variability remains striking. Clearly, some individuals ventilate way more than others to perform the same tasks. Subjects at the upper limit of the normal spectrum or slightly above like in the idiopathic hyperventilation syndrome complain of shortness of breath and are permanently hypocapnic [5].

WeAtherald et al. [3] discuss the two mean determinants of increased $V^{\prime} \mathrm{E} / V^{\prime} \mathrm{CO}_{2}$ : increased chemosensitivity and altered alveolar ventilation/perfusion $\left(V^{\prime} \mathrm{A} / Q^{\prime}\right)$ matching [3]. This differential diagnosis relies basically on a measurement of arterial partial pressure of carbon dioxide $\left(P_{\mathrm{aCO}}\right) . \mathrm{An}$ increase in $V^{\prime} \mathrm{E} / V^{\prime} \mathrm{CO}_{2}$ caused by an increased chemosensitivity is inevitably associated with hypocapnia, except when $V^{\prime} \mathrm{E}$ cannot increase because of disease-related mechanical constraint on the respiratory system. Excessive ventilation of high $V^{\prime} \mathrm{A} / \mathrm{Q}^{\prime}$ regions, or increased dead space ventilation does not affect $\mathrm{PaCO}_{2}$. However, as underscored by WeATHERALD et al. [3], when both determinants of increased $V^{\prime} \mathrm{E} / V^{\prime} \mathrm{CO}_{2}$ coexist, quantifying the contribution of each is not simple.

Assessment of altered $V^{\prime} \mathrm{A} / Q^{\prime}$ relationships can be done by a calculation of physiologic dead space (VD/ $V$ Tphys) using the Enghoff-Bohr equation, that is dead space volume $(V D)$ divided by tidal volume $(V T)$, $V \mathrm{D} / V \mathrm{~T}=\left(P_{\mathrm{aCO}_{2}}-\mathrm{EtCO}_{2}\right) / \mathrm{PaCO}_{2}$ where $P \mathrm{ETCO}_{2}$ is mixed expired partial pressure of carbon dioxide.

Received: Dec 052017 | Accepted: Dec 052017

Conflict of interest: None declared.

Copyright OERS 2018 
Physiologic dead space encompasses the ventilation to conducting airways with no gas exchange (or anatomic dead space) and to alveoli which do not eliminate carbon dioxide (or alveolar dead space). In healthy subjects $V \mathrm{D} / V$ Tphys is approximately equal to anatomic dead space [6]. When $V \mathrm{D} / V T$ phys is increased, more ventilation is needed to maintain gas exchange at any metabolic rate and normocapnia. Central and peripheral chemoreceptors inform the respiratory centre of breath-by-breath changes in $\mathrm{PaCO}_{2}$ allowing for feedback-adjusted ventilation [7]. Thus, theoretically both increased chemosensitivity and high $V^{\prime} \mathrm{A} / Q^{\prime}$ components of increased $V^{\prime} \mathrm{E} / V^{\prime} \mathrm{CO}_{2}$ can be determined by a $V \mathrm{D} / V$ Tphys calculation [2].

However, as recently reviewed by ROBERTSON [6], $V \mathrm{D} / V$ Tphys increases not only in case of lung regions with higher than normal $V^{\prime} \mathrm{A} / Q^{\prime}$, but also with shunting $\left(V^{\prime} \mathrm{A} / Q^{\prime}=0\right)$, globally altered $V^{\prime} \mathrm{A} / Q^{\prime}$ matching, decreased lung diffusing capacity and, importantly: increased ventilation. An increased $V \mathrm{D} / V \mathrm{Tphys}$ caused by increased ventilation at unchanged $V^{\prime} \mathrm{A} / Q^{\prime}$ matching was already mathematically predicted by WeST [8] in the late 1960s. Inert gas elimination studies confirmed that hyperventilation shifts retention minus excretion versus solubility relationships to higher solubility, which inevitably increases gradients for the most soluble gases and increases the calculated $V \mathrm{D} / V$ Tphys [6].

Yet insight into the differential diagnosis between increased chemosensitivity and altered $V^{\prime} \mathrm{A} / Q^{\prime}$ as causes of hyperventilation can be obtained graphically by plotting $V^{\prime} \mathrm{E} / V^{\prime} \mathrm{CO}_{2}$ as a function of $P_{\mathrm{aCO}}$, as was time ago proposed by JoHNSON [9] to identify increased dead space ventilation in patients with advanced chronic heart failure (CHF). This is illustrated in figure 1 with measurements taken at the anaerobic threshold during an exercise test in patients with compensated CHF, pulmonary arterial hypertension $(\mathrm{PAH})$ and chronic obstructive pulmonary disease (COPD) from our database. Hyperventilation shifts data points to lower alveolar partial pressure of carbon dioxide $\left(\mathrm{PACO}_{2}\right.$; estimated by $\left.P \mathrm{ETCO}_{2}\right)$ and higher $V^{\prime} \mathrm{E} / V$ ${ }^{\prime} \mathrm{CO}_{2}$ as predicted by the alveolar ventilation equation. Altered $V^{\prime} \mathrm{A} / Q^{\prime}$ increases the gradient between $P \mathrm{ETCO}_{2}$ and $\mathrm{PaCO}_{2}\left(P(\mathrm{a}-\mathrm{ET}) \mathrm{CO}_{2}\right)$ at all levels of $V^{\prime} \mathrm{E} / V^{\prime} \mathrm{CO}_{2}$. The $P(\mathrm{a}-\mathrm{ET}) \mathrm{CO}_{2}$ gradient is normally around zero or slightly negative. The upper limit of normal of $P(\mathrm{a}-\mathrm{ET}) \mathrm{CO}_{2}$ is $5 \mathrm{mmHg}$ at rest but may increase somewhat at high levels of exercise. In figure 1, patients with $\mathrm{CHF}$ (and no congested lungs) hyperventilated because of increased chemosensitivity as their $V^{\prime} \mathrm{E} / V^{\prime} \mathrm{CO}_{2}$ versus $\mathrm{PaCO}_{2}$ coordinates were on an extrapolation of normal $V^{\prime} \mathrm{E} / V^{\prime} \mathrm{CO}_{2}$ versus $\mathrm{PETCO}_{2}$ or $\mathrm{PaCO}_{2}$ relationships, patients with $\mathrm{PAH}$ hyperventilated because of increased chemosensitivity but with an additional small component of dead space ventilation, and patients with COPD hyperventilated because of increased chemosensitivity and dead space in variable proportions. A similar analysis has been previously applied to show a more important contribution of dead space ventilation in chronic thromboembolic PH compared to PAH [10].

The $V^{\prime} \mathrm{E} / V^{\prime} \mathrm{CO}_{2}$ versus $\mathrm{PaCO}_{2}$ plot may thus be more informative than $V \mathrm{D} / V$ Tphys to differentiate pulmonary and extrapulmonary determinants of hyperventilation. As also discussed by WEATHERALD et al. [3] it is important to avoid under-estimation or over-estimations of $\mathrm{PACO}_{2}$ by $\mathrm{PETCO}_{2}$ in patients with abnormal breathing patterns [3]. This problem is minimised by measuring $P(\mathrm{a}-\mathrm{ET}) \mathrm{CO}_{2}$ at the anaerobic threshold. It remains that $P(\mathrm{a}-\mathrm{ET}) \mathrm{CO}_{2}$ is a small number, sensitive to errors of measurement, and therefore to be determined with great care and cautious interpretation. Surrogates to $\mathrm{PaCO}_{2}$ are best avoided. One does not

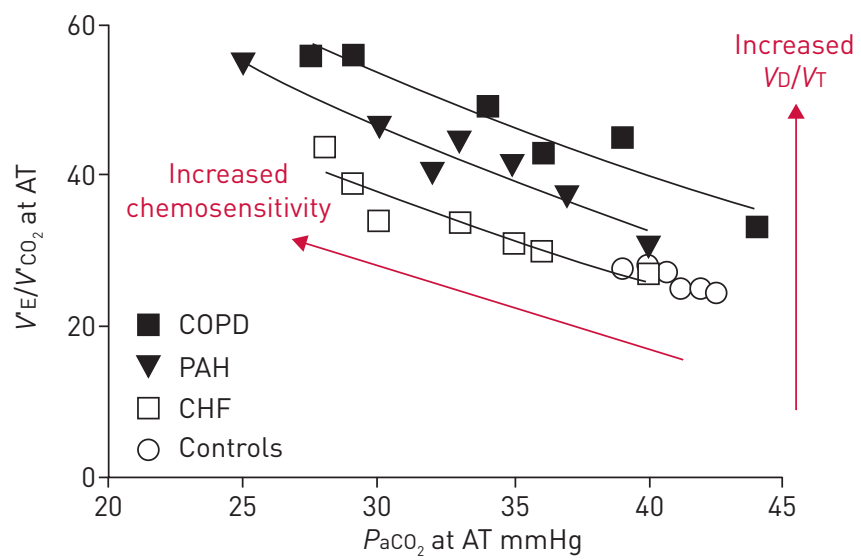

FIGURE 1 Plots of ventilatory equivalent for carbon dioxide $\left(V^{\prime} E / V^{\prime} \mathrm{CO}_{2}\right)$ as a function of arterial partial pressure of carbon dioxide $\left(\mathrm{PaCO}_{2}\right)$ measured at the anaerobic threshold (AT) in seven patients with pulmonary arterial hypertension (PAH), seven patients with chronic heart failure (CHF), seven patients with chronic obstructive pulmonary disease (COPD) and six normal controls. A leftward shift of $V^{\prime} E / V^{\prime} \mathrm{CO}_{2}$ versus $P a \mathrm{CO}_{2}$ plots to higher $V^{\prime} E / V^{\prime} \mathrm{CO}_{2}$ indicates an increased chemosensitivity. An upward shift of the $V^{\prime} \mathrm{E} / \mathrm{V}^{\prime} \mathrm{CO}_{2}$ versus $\mathrm{PaCO}_{2}$ plots discloses an increased dead space ventilation (VD/VT). 
know for example if the carbon dioxide partial pressure gradient maintains its diagnostic accuracy when $\mathrm{PaCO}_{2}$ is replaced by capillary partial pressure of carbon dioxide measurement as it is the practice in some exercise laboratories.

How relevant is this physiology? Treatment of causal respiratory or cardiac conditions to improve $V^{\prime} \mathrm{A} / Q^{\prime}$ and thereby decrease $V^{\prime} \mathrm{E} / V^{\prime} \mathrm{CO}_{2}$ is the obvious first step in a breathless patient. This includes for example bronchodilators in patients with severely obstructed airways or diuretics for heart failure patients with congested lungs. However, breathlessness may remain refractory. It is therefore curious that there has not been more development of treatments targeting specifically the chemoreceptors. Opiates have been shown to improve dyspnoea and decrease $V^{\prime} \mathrm{E} / V^{\prime} \mathrm{CO}_{2}$ without altering aerobic exercise capacity in patients with advanced heart failure [11] or emphysema [12], and in athletes at high levels of exercise [13]. However, addiction to these drugs is a concern. Selective carotid body denervation, initially reported more than half a century ago for the treatment of intractable asthma in children [14] has been shown to improve dyspnoea and quality of life in chronic lung disease [15] and in heart failure [16]. However, the procedure carries a risk of potentially fatal worsening of hypoxaemia and hypercapnia by excessive impairment of ventilatory control [17]. Deaths of chemodenervated children have been reported during underwater swims [17]. Thus carotid body denervation has remained controversial [18]. Easier and more straightforward ways to control excessive chemosensitivity include of course supplemental oxygen in hypoxaemic patients, and exercise training to decrease afferent muscle ergoreflex signalling and delay onset of metabolic acidosis [3]. All these therapeutic options should be carefully considered for patients plagued by permanent breathlessness.

Shortness of breath makes patients' lives miserable and is associated with decreased survival. The report by WeATHERALD et al. [3] is timely, as the authors remind us of the therapeutic relevance of correct pathophysiological reasoning in respiratory medicine, the utmost importance of cardiopulmonary exercise testing with arterial blood sampling in the evaluation of dyspnoea, and wasted ventilation and dyspnoea being linked as inseparable villains. Their thoughtful analysis of the relationships between ventilatory control and pulmonary gas exchange to uncover and quantify the pulmonary and extrapulmonary contributors to dyspnogenic hyperventilation is a call for improved care of breathless patients and improved specific drug development.

\section{References}

1 Burki NK, Lee LY. Mechanisms of dyspnea. Chest 2010; 138: 1198-1201.

2 Laviolette L, Laveneziana P, ERS Research Seminar Faculty. Dyspnoea: a multidimensional and multidisciplinary approach. Eur Respir J 2012; 43: 1750-1762.

3 Weatherald J, Sattler C, Garcia G, et al. Ventilatory response to exercise in cardiopulmonary disease: the role of chemosensitivity and dead space. Eur Respir J 2018; 51: 1700860.

4 Sun X-G, Hansen JE, Garatachea N, et al. Ventilatory efficiency during exercise in healthy subjects. Am J Respir Crit Care Med 2002; 166: 1443-1448.

5 Jack S, Rossiter HB, Pearson MG, et al. Ventilatory responses to inhaled carbon dioxide, hypoxia, and exercise in idiopathic hyperventilation. Am Rev Respir Dis 2004; 170: 118-125.

6 Robertson HT. Dead space: the physiology of wasted ventilation. Eur Respir J 2015; 45: 1704-1716.

7 Dempsey JA, Smith CA. Pathophysiology of human ventilatory control. Eur Respir J 2014; 44: 495-512.

8 West JB. Effects of ventilation-perfusion inequality on over-all gas exchange studied in computer models of the lung. Respir Physiol 1969; 7: 88-110.

9 Johnson RL. Gas exchange efficiency in heart failure II. Circulation 2001; 103: 916-918.

10 Zhai Z, Murphy K, Tighe H, et al. Differences in ventilatory inefficiency between pulmonary arterial hypertension and chronic thromboembolic pulmonary hypertension. Chest 2011 ; 140: 1284-1291.

11 Chua TP, Harrington D, Ponikowski P, et al. Effects of dihydrocodeine on chemosensitivity and exercise tolerance in patients with chronic heart failure. J Am Coll Cardiol 1997; 29: 147-152.

12 Light R W, Muro JR, Sato RI, et al. Effect of oral morphine on breathlessness and exercise tolerance in patients with chronic obstructive pulmonary disease. Am Rev Respir Dis 1989; 139: 126-133.

13 Martin BJ, Zwillich CW, Weil JV. Morphine reduces ventilation without changing metabolic rate in exercise. Med Sci Sports Exerc 1980; 12: 285-287.

14 Nakayama K. Surgical removal of the carotid body for bronchial asthma. Dis Chest 1961; 40: 595-604.

15 Vermeire P, de Backer W, van Maele R, et al. Carotid body resection in patients with severe chronic airflow limitation. Bull Eur Physiopathol Respir 1987; 23: Suppl. 11, 165-166.

16 Niewiński P, Janczak D, Rucinski A, et al. Carotid body removal for treatment of chronic systolic heart failure. Int J Cardiol 2013; 168: 2506-2509.

17 Severinghaus JW. Carotid body resection for COPD? Chest 1989; 95: 1128-1129.

18 Winter B. Carotid body resection: controversy-confusion-conflict. Ann Thor Surg. 1973; 16: 648-659. 